\title{
Para una ética de la estructuración farmacológica de las relaciones sociales
}

\author{
Fernando Lolas Stepke \\ Centro Interdisciplinario de Estudios de Bioética, \\ Universidad de Chile, Santiago de Chile
}

\begin{abstract}
Recibido: 21 de noviembre del 2017 / Aceptado: 26 de enero del 2018 doi: https://doi.org/10.26439/persona2018.n021.1992
\end{abstract}

El autor desarrolla una serie de consideraciones acerca de las dimensiones éticas en el empleo de las sustancias psicoactivas, distinguiendo tres efectos: los terapéuticos o médicos, los lúdicos o recreacionales, y los mejoradores de la función. Asimismo, toma en cuenta la autoadministración y la heteroadministración. Siendo el resultado de largos y complejos procesos de investigación, ensayos y empleos, en los cuales el factor económico juega un rol muy importante, las sustancias psicoactivas han modificado mucho de lo que conocemos de la naturaleza humana. Una detenida discusión sobre las dimensiones éticas de estas y también de los aspectos legales es urgente.

\section{ética / sustancias psicoactivas / naturaleza humana}

\section{Towards an Ethical Approach of the Pharmacological Structure of Social Relations}

In this study, the author analyzes a series of considerations regarding the ethical aspects of using psychoactive substances, which he classifies into three types: medical or therapeutic, recreational, and performance-enhancing. He also discusses the problems around selfadministration and administration by others of such substances. Psychoactive substances have given rise to long and thorough researches, assays and uses, in which economic factors play an important role, and have modified our knowledge of human nature. Therefore, it is urgent to discuss the ethical and legal aspects of their future use. 
Una sustancia psicoactiva es aquella cuyo efecto principal se ejerce sobre el sistema nervioso central (SNC). Es necesario agregar, por cierto, que esta acción debe traducirse en cambios en la fisiología, la conducta o la vivencia.

Según sus usos, pueden distinguirse efectos terapéuticos o médicos, lúdicos o recreacionales y mejoradores de la función. La distinción entre un uso terapéutico y uno optimizador de la función radica en que este no pretende restablecer la normalidad, sino aumentar las potencialidades (Silva, 2016).

En cuanto a las formas de administración, puede tratarse de heteroadministración cuando una persona distinta del usuario indica o administra, o de autoadministración, en la cual el usuario, por propia iniciativa, ingiere o se inyecta una sustancia. Esta distinción es de suma relevancia, toda vez que una especialidad farmacéutica correctamente indicada puede ser usada con fines distintos de los aprobados. En este caso, aunque se trata de una indicación, el uso no es compatible con la noción de administración por otros.

Los usos recreacionales o lúdicos pueden contemplar tanto sustancias aprobadas para uso terapéutico, como drogas, y principios activos no aprobados o ilegales (Dolengevich-Segal et al., 2017). Las regulaciones toman en cuenta el potencial de crear dependencia o la injusticia que puede significar disponer de algo no accesible a todo el mundo.

Cada uno de estos usos plantea dilemas éticos; tanto en la indicación con fines terapéuticos, como en la regulación del uso no terapéutico. Obsérvese que la calificación de uso terapéutico es variable y puede cambiar según estudios y experiencias. Por ejemplo, cannabis y derivados pueden entrar en la categoría de fármacos, pero solamente a condición de que demuestren eficacia en contextos clínicos (Lolas, 2016).

\section{ConsideraCiONES GENERALES}

Los aspectos que deben tenerse en cuenta para el análisis ético son, en realidad, numerosos. Aquí solo señalaremos algunos de los más relevantes:

\section{Mecanismo de acción y duración de los efectos}

Junto a los estudios de biodisponibilidad y farmacocinética, son esenciales para evaluar los efectos a corto, mediano y largo plazo.

En general, los fármacos desarrollados por la industria se basan en moléculas sometidas a un riguroso proceso de desarrollo y ensayo in vitro (pruebas químicas), in silico (simulación computacional), in vivo (estudios en animales) y en seres humanos (ensayos clínicos y pruebas de tolerancia). Esos fármacos tienen indicaciones precisas avaladas por autoridades competentes, que regulan desde el proceso de fabricación hasta la concesión y resguardo de las patentes de propiedad intelectual.

El mecanismo de acción puede ligarse a los efectos clínicos de modo más o menos directo, aunque en ocasiones las 
conclusiones no son simples. Puede que se evidencien efectos bioquímicos en plazos breves, pero sus repercusiones sobre la conducta o sobre el estado de ánimo pueden tardar en manifestarse, como es el caso de algunos fármacos rotulados como antidepresivos.

En general, una sustancia ejerce efectos en muchos sistemas neurobioquímicos, de manera que ligar sus efectos manifiestos a uno $u$ otro es materia de investigación empírica y de rotulación, según su efecto más destacado.

Igual acontece con los efectos laterales, indeseados o secundarios; a veces no pueden anticiparse con exactitud y dependen de propiedades distintas de las bioquímicas (por ejemplo, asociación con otros compuestos, hipersensibilidad, expectativas de efectos).

\section{Perfil del efecto sobre la conducta, la vivencia y la fisiología}

El efecto de una sustancia en el SNC se mide mediante pruebas que evalúan la atención, los sentimientos depresivos, la ideación y cualquier constructo de naturaleza observacional.

Es esencial tener presente que la elección del instrumento de evaluación determina lo que se conocerá como efecto. Esto es, si no se aplican pruebas de rendimiento atencional, nada se podrá concluir sobre este factor. Si se utiliza una prueba de rendimiento cognitivo, habrá muchas dimensiones inexploradas.

Por ende, cada indicación o efecto dependerá críticamente de un muestreo aleatorio de efectos y no necesariamente los que se estudie serán los más importantes, aunque sean los más relevantes para la indicación terapéutica. Su interés está dictado por el eventual empleo de la sustancia. Muchos efectos han sido descubiertos por azar (serendipity), como es el caso de la dietilamida de acido lisérgico (LSD) y sus derivados.

En relación con las pruebas psicométricas, debe observarse que algunas están orientadas a evaluar rasgos, mientras que otras se concentran en estados. La distinción rasgo-estado es compleja y muchas sustancias químicas, si bien pueden alterar transitoriamente la vivencia y la conducta, carecen de influencia sobre rasgos duraderos de las personas. Un rasgo puede definirse como una disposición conductual o vivencial relativamente duradera que cualifica las acciones de las personas. Su estructura suele agruparse bajo el concepto de personalidad. Los rasgos son interesantes de estudiar cuando se examinan estados transitorios. Un síntoma cualquiera se modifica según el sustrato de personalidad de quien lo experimenta o comunica.

Dentro de estas consideraciones entra también la dosificación y la posología, que afectan seriamente el tipo y la duración de los efectos sobre conducta y fisiología.

\section{Variabilidad debida a la persona $y$ el contexto}

Siempre cabe esperar reacciones idiosincráticas a la administración de una 
sustancia química. Los efectos placebo y nocebo son situaciones ejemplares, por lo extremas.

Un contexto de administración confiado y optimista produce mejores y más duraderos efectos que una indicación temerosa. En las drogas lúdicas, la expectativa de efectos positivos se ve acrecentada por el entorno, a veces grupal, en que se las emplea.

Predisposiciones genéticas o vulnerabilidades no conocidas pueden precipitar efectos adversos al usar sustancias psicotrópicas. Muchos no pueden anticiparse ni preverse.

\section{Aceptabilidad social y regulaciones existentes para sustancias con efecto psicoactivo}

Respecto a las sustancias de uso recreacional, su aceptación social o su rechazo dependen de factores diversos: la moda, la accesibilidad económica, el efecto demostración por clase social o cultura, entre otros.

La mayoría de las sustancias legales con efectos psicotrópicos están sometidas a regulaciones. Por ejemplo, las benzodiacepinas se controlan por la posibilidad de adicción y por efectos importantes en la atención, si no se administran con resguardos médicos apropiados. Lo propio cabe decir de otras sustancias con mayor o menor riesgo, según dosificación y contexto de uso.

En lo que se refiere al uso médico, muchas personas resienten el empleo de algunos tranquilizantes por suponer que afectará sus capacidades, los hará dependientes e impedirá una evolución sana. La indicación farmacológica, además de estar avalada por datos serios, incluye la convicción del médico sobre los potenciales beneficios.

\section{Aunque relacionada}

\section{con la anterior, la accesibilidad económica merece consideración especial}

Cuando una sustancia es rotulada como medicamento, existe la convicción de que debe estar disponible en los sistemas de salud. No es exigible un fármaco en fase de ensayos o una sustancia cuya indicación terapéutica no está establecida. La accesibilidad económica de un medicamento es parte de la ideología dominante en muchos sectores, aunque en la realidad no sea universal.

No debe olvidarse este aspecto al considerar las drogas lúdicas o recreacionales. El factor económico en su uso es responsable de delincuencia, organizaciones delictivas o criminales y connotaciones políticas.

\section{Todo uso de sustancias, como otras tecnologías sociales, entra al juego de prohibiciones y permisos propios de la vida social}

Son relevantes, para cada uso de sustancias psicotrópicas - terapéutica, recreación o mejoramiento-, consideraciones sobre la autonomía de las personas, confidencialidad y privacidad, efectos negativos en otras personas, etcétera. 


\section{LOS FÁRMACOS SON COMPONENTES DE SISTEMAS SOCIOTÉCNICOS}

La ubicuidad de las intervenciones farmacológicas, terapéuticas o lúdicas, muestra que la tecnología está presente en todo sistema social. Estos artefactos - los fármacos - modifican lo que creemos conocer sobre la vida humana. Ya esta no existe en ninguna forma natural. Salvo prohibiciones rituales o ausencia de medios, en todo el mundo se bebe café o té, a veces también se usa alcohol o tabaco, por no hablar de las drogas dietéticas que se consumen en los alimentos elaborados, desde colorantes hasta saborizantes.

Cualquier retorno a lo natural, aunque sea argumento de mercadeo, es ilusorio. Ya estamos en la artificialidad de una segunda naturaleza. Los fármacos son solo un componente, y quizá no el más visible, de la artificialización (tecnificación) de la vida humana. En ciertos lugares del mundo, una vida sin artefactos electrónicos de comunicación es impensable (Rohbeck, 1993).

Los fármacos representan una compresión de saber científico y tecnología en un artefacto de fácil acceso. La misma voz, comprimido, con que se designa la presentación de algunos de ellos puede tomarse como alusión a esta compresión de tecnología. Tras cada fármaco hay toda una trama de procesos constructivos, tanto de descubrimiento como de invención; que a veces restauran, a veces crean y a veces mejoran, funciones.

\section{LA HOMEOSTASIS SOCIAL MEDIADA} FARMACOLÓGICAMENTE

El término homeostasis, de larga tradición en las ciencias de la salud, alude a la constancia del medio interno necesaria para la correcta realización de las funciones orgánicas.

Existen dos formas de homeostasis. Una, que podría llamarse interna, depende de mecanismos fisiológicos establecidos por la evolución biológica. Así, la temperatura en muchas especies, la glicemia, los electrolitos sanguíneos, se regulan por mecanismos automáticos e inconscientes.

Otra forma de homeostasis depende de la conducta. Algunos seres vivos regulan la temperatura corporal solamente cambiando de ambiente, como es el caso de ciertas especies de peces. La creación de condiciones apropiadas y el empleo de dispositivos comportamentales se agregan así a las regulaciones fisiológicas y bioquímicas del organismo.

El término homeostasis puede ser extendido también al comportamiento de grupos humanos. La homeostasis psicológica depende de mecanismos regulatorios de las motivaciones, las emociones y las cogniciones. Hay menoscabos, discapacidades y minusvalías que pueden afectar, transitoria o permanentemente, la regulación de los rendimientos y el bienestar psíquico. 
La homeostasis social es un fenómeno que puede postularse como resultado de equilibrios entre disposiciones, contextos y circunstancias que afectan la vida de un grupo. La definición de grupo, aunque siempre difícil, puede servir para delimitar los alcances y límites del campo de estudio.

En ambos tipos de homeostasis cuya traducción al lenguaje de la ética podría ser la obtención y manutención de la vida buena- la intervención de agentes farmacológicos es innegable. Especialmente en el caso de los fármacos psicotrópicos, su uso plantea importantes desafíos desde el punto de vista ético.

\section{ÉTICA SOCIAL Y ÉTICA INDIVIDUAL}

No existe acción humana que no pueda ser enjuiciada. Puede ser por el propio sujeto, a partir de emociones morales, o por la comunidad, basándose en tradición, costumbre y ley.

Se aceptan drogas sociales, como el alcohol, en la medida que su uso se mantenga dentro de ciertos límites regulados por la necesidad de preservar el orden, impedir el trastorno o promover la convivencia.

Algunas drogas lúdicas pueden ser reguladas en algunas sociedades atendiendo a su potencial de adicción y lo que ello implica de limitación de las libertades individuales. Lo cual, a su vez, genera estados de dependencia que se prestan a la manipulación comercial y el tráfico ilegal.

Otros fármacos, como los empleados en la terapéutica y en el mejoramiento de las capacidades, exigen regulación por potenciales efectos laterales o por afectar las normas de convivencia. La utilización de nootrópicos que mejoran las funciones cognitivas o la atención plantea problemas semejantes al doping deportivo. Confieren - o podrían conferir, pues no siempre es el caso- una ventaja que, de no conocerse o declararse, podría llevar a interacciones sociales desiguales o injustas. Su adquisición, en caso de demostrarse indispensables, plantea el problema del acceso equitativo, argumento que suele utilizarse para la distribución y comercialización de medicamentos.

Estas consideraciones, sumariamente, apuntan a la necesidad de revisar las pautas de comportamiento ético en relación con los psicotrópicos y su expresión en normas legales y técnicas (Lolas, 2016). En cada caso, el plano individual y el colectivo deben considerarse simultáneamente y permitir el libre ejercicio del diálogo y la expresión de deseos, necesidades y demandas sociales (Lolas y Cornejo, 2017). 


\section{REFERENCIAS}

Dolengevich-Segal, H., Rodríguez-Salgado, B., Gómez-Arnau, J., y Sánchez-Mateos, D. (2017). An approach to the new psychoactive drugs phenomenon. Salud Mental 40(2): 71-82.

Lolas, F. (2016). Bioética y psicofarmacología. En Silva, H. (Ed.), Manual de psicofarmacología clínica (2. ed.). Santiago de Chile: Mediterráneo.

Lolas, F., y Cornejo, I. (2017). Neurociencias, neuroética y derecho: culturas epistémicas y comunidades de práctica. Jurisprudencia Argentina, número especial de bioética II, 64-72.

Rohbeck, J. (1993). Technologische Urteilskraft. Zu einer Ethik technischen Handelns. Frankfurt: Suhrkamp.

Silva, H. (2016) Manual de psicofarmacología clínica. (2. ${ }^{\text {a }}$ ed.). Santiago de Chile: Mediterráneo. 